\title{
Simple advice to reduce salt intake
}

The effect of dietary salt on health has caused much debate and a seemingly ongoing battle between the medical fraternity and the food industry. ${ }^{1}$ In the UK, more than the US, this appears to be being won by the medical establishment with a greater public awareness of salt consumption through government campaigns and improved food labelling. ${ }^{2}$ As yet, it is not clear whether these added measures have had a net effect in actually reducing sodium intake and although food products are being labelled more clearly, many continue to contain large amounts of added salt. The scientific data meriting reduced sodium intake also continues to mount. A Cochrane review states that in hypertensive patients a modest reduction in dietary salt intake over 4 or more weeks led, on average, to a decrease of $4.7 \mathrm{mmHg}$ systolic blood pressure and $2.7 \mathrm{mmHg}$ diastolic blood pressure, although it was unclear in this study whether the same reduction in salt intake lead to a decrease in cardiovascular risk or mortality. ${ }^{3}$ A subsequent study by The Trials of Hypertension Prevention Collaborative Research Group confirmed that reduced sodium intake lowers blood pressure in addition to the possible reduction of long-term cardiovascular events. ${ }^{4}$ With increasing evidence to recommend a reduced sodium intake the Food Standards Agency recommends that we should all aim to consume no more than $6 \mathrm{~g}$ of salt ( $2.5 \mathrm{~g}$ sodium) a day. ${ }^{2}$ This figure represents a compromise between the average daily UK consumption of $(9-12 \mathrm{~g})$ and what we actually need (1-2 g).

With the mounting scientific data and government backing it is quite understandable that clinicians want clearer guidance as to how to translate methodology from successful trials into advice to a patient sitting in front of them in a consultation. ${ }^{5}$ Several of the published trials concluding that dietary salt reduction leads to a decrease in blood pressure do not give details of the advice that patients were given to reduce their overall salt intake. Other trials had tightly controlled diets where all meals in control and lowsalt groups were provided for. Being able to extrapolate the results of these trials to public awareness and practice would be useful, providing the advice is both easy to understand and to follow. The first step must therefore be to put the reason for the intervention into context. Thus emphasising that even a modest (2 g) reduction of salt intake, over a relatively short period, can lead to a reduction in blood pressure, which could lead to a decreased incidence of stroke in the long term. We suggest that further advice can be delivered using a quick and easy acronym: S.A.L.T. (Box 1).

\section{STAY AWAY FROM PROCESSED FOODS}

It has been stated that as much as $75-80 \%$ of our dietary salt can come from processed foods. ${ }^{6}$ This so called 'hidden salt' is often added to please taste buds which grow ever more dependent upon high-salt content foods. For example, a single slice of processed cheese may contain more sodium than an entire bag of crisps. A simple way of achieving a modest reduction therefore, would be to reduce the consumption of processed supermarket, canteen, restaurant, and fast food.

\section{AVOID ADDING SALT TO FOODS}

The simple measure of removing salt from the table and in cooking (for example, when boiling pasta) could cut salt consumption significantly. This is especially important when you consider that half a teaspoon of salt will contain approximately half the daily allowance $(3 \mathrm{~g})$. Seeking low-salt recipes may be another way and the Food Standards

\section{Box 1. S.A.L.T.}

Stay away from processed foods

Avoid adding salt to foods

Look at sodium levels

Try to eat a balanced diet
Agency provides links to sites that can give such information. ${ }^{?}$

\section{LOOK AT SODIUM LEVELS}

We should be advising patients to be more aware of their salt consumption through greater awareness of sodium levels on nutritional labels. Patients could be advised to examine sodium levels in the same way they might count calories or fat intake. Six grams of sodium equates to approximately a level teaspoon of salt per day although a quick glance at labelling on food packaging suggests that we are likely to be consuming much more than that probably without even realising (Table 1). For example, a breakfast of cereal, two slices of toast with peanut butter and margarine contains nearly $2.5 \mathrm{~g}$ of salt whereas a single large hamburger from a high street chain may contain almost your entire recommended daily intake of salt. Of particular interest is the possibility that low fat alternatives compensate loss of taste through sweetness by increasing salt levels.

\section{TRY TO EAT A BALANCED DIET}

The Dietary Approaches to Stop Hypertension (DASH) study revealed that a diet low in saturated fat and cholesterol but high in protein, carbohydrate, potassium, calcium, and magnesium resulted in reduced blood pressure when compared with a representative average Western diet. ${ }^{8}$ When the DASH diet was combined with a lower sodium intake the reduction of blood pressure was compounded. ${ }^{9}$ As a result the National Institute of Health now recommends the DASH eating plan. ${ }^{10}$ This DASH data supports the finding that a low sodium, high potassium and magnesium cooking salt could reduce blood pressure when substituted for normal salt. ${ }^{11}$ Although it is worth noting that issues were raised concerning the design of this trial and the cost-effectiveness of this mineral salt. ${ }^{12}$ Nevertheless a diet containing potassiumrich foods, such as bananas, avocados, dried fruit, seeds, tomato juice, and salad vegetables, as well as magnesium-rich 
Table 1. Salt content of common foods.

\begin{tabular}{lcc} 
Food item & $\begin{array}{c}\text { Sodium (g)/ serving } \\
\text { (Max 2.5 g/day) }\end{array}$ & $\begin{array}{c}\text { Salt (g)/ serving } \\
\text { (Max 6 g/day) }\end{array}$ \\
\hline Wheat biscuit cereal (without milk) & 0.24 & 0.60 \\
\hline 1 slice brown bread & 0.18 & 0.40 \\
\hline 1 rasher streaky bacon & 0.36 & 0.90 \\
\hline Small packet crisps & 0.20 & 0.50 \\
\hline One processed cheese single slice & 0.28 & 0.70 \\
\hline Peanut butter & 0.15 & 0.40 \\
\hline Margarine & 0.06 & 0.10 \\
\hline Canned tomato soup (half can) & 0.60 & 1.50 \\
\hline High street 'fast food' large hamburger & 2.25 & 5.40 \\
\hline High street 'fast food' medium French fries & 0.55 & 1.30 \\
\hline 1 slice pizza & 0.55 & 1.30 \\
\hline Salt cellar with multiple holes & 0.40 & 1.00 (per shake) \\
\hline Apple (one medium sized) & $<0.01$ & $<0.01$ \\
\hline 1 'skinny' blueberry muffin (high street coffee shop) & 0.60 & 1.54 \\
\hline 1 regular blueberry muffin (high street coffee shop) & 0.45 & 1.00 \\
\hline
\end{tabular}

foods, such as leafy green vegetables, nuts, seeds, and oats, may provide additional benefits when combined with a low sodium intake (as suggested before) in reducing blood pressure.

As with many lifestyle interventions, problems can be anticipated from patients with regard to the adjustment in taste to a lower salt diet and compliance with it. However, with greater awareness from the media and sensible advice from health professionals, salt reduction may prove to be a readily accessible, non-drug intervention, as well as a significant way of reducing public ill health in the long term.

\section{Kamal R Mahtani}

\section{Acknowledgements}

$\mathrm{Dr}$ Joe Rosenthal (Academic Lead in Primary Care Medicine, University College London) for advising on the manuscript.

\section{REFERENCES}

1 Sharp D. Labelling salt in food: if yes, how? Lancet 2004 Dec 11-17; 364(9451): 2079-81.

2. Food Standards Agency. No more than $6 \mathrm{~g}$. http://www.salt.gov.uk/no_more than_6.html (accessed 7 Sep 2009).

3. He FJ, MacGregor GA. Effect of longer-term modest salt reduction on blood pressure. Cochrane Database Syst Rev 2004; (3): CD004937

4. Cook NR, Cutler JA, Obarzanek E, et al. Long term effects of dietary sodium reduction on

cardiovascular disease outcomes: observational follow-up of the trials of hypertension prevention (TOHP). BMJ 2007; 334: 885-888.

5. Glasziou PP. Sodium reduction is enticing, but what is the full recipe? BMJ 2007; 334(7601): 967.

6. He FJ, MacGregor GA. Salt in food. Lancet 2005; 365(9462): 844-845.

7. Food Standards Agency. Eat well, be well. Helping you make healthier choices.

http://www.eatwell.gov.uk/healthydiet/recipes/ (accessed 10 Sep 2009).

8. Appel LJ, Moore TJ, Obarzanek E, et al. A clinical trial of the effects of dietary patterns on blood pressure. DASH Collaborative Research Group. $N$ Engl J Med 1997; 336(16): 1117-1124.

9. Sacks FM, Svetkey LP, Vollmer WM, et al. Effects on blood pressure of reduced dietary sodium and the Dietary Approaches to Stop Hypertension (DASH) diet. DASH-Sodium Collaborative Research Group. N Engl J Med 2001; 344(1): 3-10.

10. National Institute of Health. Your Guide to Lowering Your Blood Pressure with DASH.

http://www.nhlbi.nih.gov/health/public/heart/hbp/da $\mathrm{sh} /$ (accessed 7 Sep 2009).

11. Geleijnse JM, Witteman JC, Bak AA, et al. Reduction in blood pressure with a low sodium, high potassium, high magnesium salt in older subjects with mild to moderate hypertension. BMJ 1994; 309(6952): 436-440.

12. Fielder H, Lo SV. Effect of dietary mineral salt on blood pressure. Study methods flawed. BMJ 1994; 309(6962): 1157. 